\title{
Evaluation of Bone Densitometry in Rheumatoid Arthritis Case Control Study \\ Shwan Kader Media $(\mathrm{PhD})^{1}$
}

\author{
${ }^{1}$ College of Medicine, Hawler Medical University, Iraq \\ email: mediashwan@hotmail.com mobile 096407505190000
}

Received: 19 October 2020

Revised: 23 October 2020

Accepted: 29 November 2020

Published: 15 April 2021

Diyala Medical Journal 2021:20(1): 50- 62

\section{Abstract}

Background: Rheumatoid arthritis is a systemic autoimmune inflammatory disease that causes joint deformity, including erosion of bone, and narrowing of the joint space. Osteoporosis is more prevalent among rheumatoid arthritis patients than in the general population.

Objective: To determine changes in the bone mineral density in rheumatoid arthritis patients and to evaluate factors were associated with bone mineral density.

Patients and Methods: In this study, 70 cases with rheumatoid arthritis were included and 70 healthy subjects on the other hand as a control group. The data were collected including socio-demographic information of all patients'age, gender, medical histories included systemic diseases, types of biological agents, use of supplements, duration of the disease, smoking, and regular exercise. Bone mineral density was evaluated by using bone densitometry in two areas including Lumber 1 to lumber 4 and neck of the left femur. Statistical analyses were performed by using Statistical Package for Social Sciences (SPSS) version 22; Fisher's exact test and Chi-square test Student's t-test of two independent samples was used to comparing two means. A p-value of $\leq 0.05$ was considered statistically significant.

Results: In the rheumatoid arthritis group according to T-spine scores the prevalence of osteoporosis was $22.9 \%$, osteopenia was $42.9 \%$ and normal bone mineral density was $34.4 \%$ compared with the control group $4.3 \%, 42.9 \%, 52.9 \%$ successively which were statistically significant difference between the two groups $(\mathrm{p}=0.003)$. According to femur neck T-scores in the rheumatoid arthritis group, $17.1 \%$ had osteoporosis, $34.3 \%$ had osteopenia and $48.6 \%$ had normal bone mineral density compared with the control group $2.9 \%, 24.3 \%, 72.9$ respectively which were statistically significant difference between the two groups $(\mathrm{p}=0.003)$. lumber spine was the commonest site affected by osteoporosis (16 cases,22.9 \%)and the second most common site was the femur neck ( 12 cases, $6.6 \%)$. The cases of 50 years and older were most commonly affected by osteoporosis ( $\mathrm{p}$-value $=0.0001$ ). No significant association was detected 
between bone mineral density (as assessed with spine T-scores and femur T-scores) with gender, duration of the disease, BMI, exercise, supplement, systemic disease, and diabetes.

Conclusion: Osteoporosis and osteopenia were considered as common complications in rheumatoid arthritis, the age of the patient also considered as a risk factor for reduced bone mineral density.

Keywords: Rheumatoid Arthritis; Bone Mineral Density; Osteoporosis; Osteopenia

\section{Introduction}

Rheumatoid Arthritis (RA) is a chronic autoimmune inflammatory disease that causes chronic inflammation of the synovial membrane, with consequent destruction and deformity. The etiology of rheumatoid arthritis it is unclear but genetic and environmental factors have a role in developing RA [1]. The manifestations of rheumatoid arthritis are not only limited to the joints, but also have extra-articular manifestations like rheumatoid nodules, vasculitis, episcleritis, pulmonary fibrosis, pericarditis, anemia, and osteoporosis $[2,3]$. The prevalence of RA approximately is $1.0 \%$ in the general population, and affects women more than men. RA patients experience pain, stiffness, tenderness, and articular damage of the joints leading to functional disability, which reduces the quality of life [4-6].

Rheumatoid arthritis is chronic inflammatory arthritis associated with changes in biochemical properties of the bone and leads to the alteration in the bone components through the increased production of the pro-inflammatory cytokines or through the effect of hormone-mediated mechanisms [7-9]. In addition to the risk factors of osteoporosis, other factors may play important role in the development of osteoporosis including physical disability, inadequate treatment, and disease activity [10-12]. Osteoporosis is more common in patients with rheumatoid arthritis than in the general population. The prevalence of concurrent osteoporosis is $50 \%$. Osteoporosis causes pain and increase the risk of fracture after falling [13]. The chronic synovial inflammation in rheumatoid arthritis promote osteoclastogenesis, which leads directly to both focal and generalized bone loss and increased risk of fracture, also there are many indirect factors that associate inflammatory arthritis contribute to the risk of osteoporosis, as weight loss, immobility, and chronic use of medicines, such as glucocorticoids [14].

Osteoclast play important role in bone resorption in rheumatoid arthritis patient, orchestrated by T-lymphocytes, monocytes, and fibroblasts in the synovium of inflammatory joints that involved in the disease processes, which produce osteoclast differentiation-inducing factors. Osteoclast differentiation is mainly promoted by the receptor activator of nuclear factor-kappa $B$ ligand (RANKL), which is up-regulated by a large number of the inflammatory cytokines involved in the pathogenesis of rheumatoid arthritis [15]. A better understanding of the pathogenesis of RA has improved treatment of the disease, particularly using biological agents and JAK-inhibitors.

It is recommended by the International Society for Clinical Densitometry (ISCD) and National Osteoporosis Foundation (NOF) 
that Dual -Energy X-ray Absorptiometry (DEXA) testing should be done for all adults rheumatoid arthritis patients, as well as women over 65years old, those who suffer a fragility fracture, patients on chronic glucocorticoids therapy and anyone at the high risk of fracture.

To evaluate bone mineral density (BMD) in patients with rheumatoid arthritis, and to establish which factors were associated with low BMD.

\section{Patients and Methods}

This prospective cross-sectional casecontrol study was conducted in Hawler Teaching Hospital Department of Rheumatology. This study was approved by the Ethical Committee at the college of Medicine in the Hawler Medical University. All the patients were signed informed consent forms before being included in the study. No therapeutic intervention was made and the patients' data were kept confidential. The study was composed of 70 patients with RA and 70 controls healthy, socioeconomic matched controls patients were taken.

Inclusion criteria: According to the American College of Rheumatology/European League Against Rheumatism ACR/EULAR 2010 criteria for rheumatoid arthritis all patients with RA are included in the study [19].

Exclusion criteria: Patients with psoriasis, inflammatory bowel disease, dementia, pregnancy, thyroid diseases secondary cases of osteoporosis, were excluded from our study.

According Declaration of Helsinki Physical examination and questionnaires the consent was obtained. The data were collected including sociodemographic variables of all patients; age, gender, medical history included, systemic disease type of biology treatment, using supplements, duration of RA, regular exercise, and smoking.

The height and weight were measured and respondents were dressed in light clothes and did not wear shoes. Body mass index (BMI) was calculated from the height and weight recorded while performing a DEXA scan. The BMI was calculated based on the formula weight $(\mathrm{kg}) /$ height $(\mathrm{m})^{2}$. The standard categorization of BMI by The Centers for Disease Control and Prevention (CDC) [20], indicates less than 18.5 as underweight, 18.5-24.9 as normal, 25.029.9 as overweight, and 30.0 and above as obese.

Bone mineral density of the lumbar spine in the anterior- posterior view (AP) (vertebrae L1 to L4), and the left femoral neck) was measured using a DXA scanner. Following World Health Organization (WHO) definitions of osteopenia and osteoporosis were used: osteopenia, T-score $<-1$ to $>-2.5$ $\mathrm{SD}$ (compared to the young normal mean), and osteoporosis, T-score $\leq-2.5 \mathrm{SD}$. The lowest value of BMD measured in the lumbar spine, the femoral neck was used [21]. For patients under the age of 50, a Z-score $\leq-2.0$ $\mathrm{SD}$ (compared to the age-matched mean) was considered to be below the expected range for age [22]. For calculation of $\mathrm{T}$ - and $\mathrm{Z}$ scores the BMD values of the patients were compared with reference values provided by the DXA scanner.

\section{Statistical analysis}

Data were analyzed using the Statistical Package for Social Sciences (SPSS, version 25). Chi-square test of association was used 
to compare proportions. Fisher's exact test was used when the expected count of more than $20 \%$ of the cells of the table was less than 5. Student's t-test of two independent samples was used to compare two means. A $\mathrm{p}$-value of $\leq 0.05$ was considered statistically significant.

\section{Results}

Seventy patients with rheumatoid arthritis had been included in the study and considered as cases, on the other hand, 70 persons with no RA were included which considered as a control group. The mean age $\pm \mathrm{SD}$ of the cases was $47.03 \pm 11.53$ years, and that of the control was $46.54 \pm 12.66$ years $(p=0.813)$. No significant differences were detected in the age distribution of cases and controls $(\mathrm{p}=0.479)$ as presented in Table (1). The majority $(87.1 \%)$ of the whole sample were females, but there was no significant difference in the gender distribution of the two groups $(\mathrm{p}=0.130)$. Around half $(50.7 \%)$ of the patients were obese, and $31.4 \%$ were overweight. Again no significant difference was detected between the two groups $(p=0.685)$. More than onethird $(37.1 \%)$ of the control group were practicing exercise, this proportion was significantly $(p=0.025)$ higher than the proportion among the cases $(20 \%)$. The table also shows that $10 \%$ of the whole sample were smokers, but the differences between the two groups were not significant $(\mathrm{p}=$ $0.260)$.

Table (1): Basic characteristics of the study groups

\begin{tabular}{|c|c|c|c|c|c|c|c|}
\hline & \multicolumn{2}{|c|}{ Case } & \multirow{2}{*}{$\begin{array}{c}\text { Control } \\
\text { No. }\end{array}$} & \multirow[b]{2}{*}{$(\%)$} & \multirow{2}{*}{$\begin{array}{l}\text { Total } \\
\text { No. } \\
\end{array}$} & \multirow[b]{2}{*}{$(\%)$} & \multirow[b]{2}{*}{ P-value } \\
\hline & No. & $(\%)$ & & & & & \\
\hline \multicolumn{8}{|l|}{ Age (years) } \\
\hline $20-29$ & 4 & (5.7) & 9 & (12.9) & 13 & $(9.3)$ & \\
\hline $30-39$ & 14 & (20.0) & 12 & (17.1) & 26 & (18.6) & \\
\hline 440-49 & 25 & (35.7) & 18 & (25.7) & 43 & (30.7) & \\
\hline (50-59 & 14 & (20.0) & 16 & (22.9) & 30 & (21.4) & \\
\hline $60-69$ & 13 & (18.6) & 15 & (21.4) & 28 & (20.0) & 0.479 \\
\hline Mean $( \pm$ SD $)$ & 47.03 & $( \pm 11.53)$ & 46.54 & $( \pm 12.66)$ & & & $0.813 \dagger$ \\
\hline \multicolumn{8}{|l|}{ Gender } \\
\hline Female & 58 & (82.9) & 64 & (91.4) & 122 & (87.1) & \\
\hline Male & 12 & (17.1) & 6 & $(8.6)$ & 18 & $(12.9)$ & 0.130 \\
\hline \multicolumn{8}{|c|}{ BMI $\left(\mathrm{Kg} / \mathrm{m}^{2}\right)$} \\
\hline$<25$ & 12 & $(17.1)$ & 13 & $(18.6)$ & 25 & $(17.9)$ & \\
\hline $25-29$ & 20 & $(28.6)$ & 24 & $(34.3)$ & 44 & $(31.4)$ & \\
\hline$\geq 30$ & 38 & (54.3) & 33 & (47.1) & 71 & (50.7) & 0.685 \\
\hline Mean $( \pm$ SD $)$ & 31.55 & $( \pm 6.94)$ & 30.08 & $( \pm 5.67)$ & & & $0.172 \dagger$ \\
\hline \multicolumn{8}{|l|}{ Exercise } \\
\hline Yes & 14 & $(20.0)$ & 26 & (37.1) & 40 & $(28.6)$ & \\
\hline No & 56 & $\begin{array}{l}(80.0) \\
\end{array}$ & 44 & $\begin{array}{l}(62.9) \\
\end{array}$ & 100 & $\begin{array}{l}(71.4) \\
\end{array}$ & 0.025 \\
\hline \multicolumn{8}{|l|}{ Smoking } \\
\hline Yes & 9 & (12.9) & 5 & $(7.1)$ & 14 & (10.0) & \\
\hline No & 61 & $\begin{array}{l}(87.1) \\
\end{array}$ & 65 & $\begin{array}{l}(92.9) \\
\end{array}$ & 126 & (90.0) & 0.260 \\
\hline Total & 70 & (100.0) & 70 & (100.0) & 140 & (100.0) & \\
\hline
\end{tabular}

*By Fisher's exact test. † By t-test for two independent samples. The others by Chi-square test 
It is evident in Table (2) that $74.3 \%$ of the controls were taking supplements, compared with $47.1 \%$ of the cases $(\mathrm{p}=0.001)$. The prevalence of diseases in the whole sample was as follows: systemic diseases (24.3\%), diabetes $(5 \%)$. All the differences between the two groups regarding the prevalence of diseases were not significant. The table shows that $24.3 \%$ of the cases were on Infliximab, $61.4 \%$ on etanercept, $7.1 \%$ on adalimumab and $7.1 \%$ were on rituximab.

Table (2): Drug intake and clinical characteristics of the two study groups

\begin{tabular}{|c|c|c|c|c|c|c|c|}
\hline & \multicolumn{2}{|c|}{ Case } & \multicolumn{2}{|c|}{ Control } & \multicolumn{2}{|c|}{ Total } & \multirow[b]{2}{*}{ P-value } \\
\hline & No. & $(\%)$ & No. & $(\%)$ & No. & $(\%)$ & \\
\hline \multicolumn{8}{|c|}{ Supplements } \\
\hline Yes & 33 & $(47.1)$ & 52 & $(74.3)$ & 85 & $(60.7)$ & \\
\hline No & 37 & (52.9) & 18 & (25.7) & 55 & (39.3) & 0.001 \\
\hline \multicolumn{8}{|c|}{ Systemic diseases } \\
\hline Yes & 19 & $(27.1)$ & 15 & (21.4) & 34 & $(24.3)$ & \\
\hline No & 51 & (72.9) & 55 & $(78.6)$ & 106 & $(75.7)$ & 0.430 \\
\hline \multicolumn{8}{|c|}{ Diabetes } \\
\hline Yes & 6 & (8.6) & 1 & (1.4) & 7 & (5.0) & \\
\hline $\mathrm{No}$ & 64 & $(91.4)$ & 69 & (98.6) & 133 & $(95.0)$ & $0.116^{*}$ \\
\hline \multicolumn{8}{|c|}{ Infliximab } \\
\hline Yes & 17 & $(24.3)$ & 0 & $(0.0)$ & 17 & $(12.1)$ & \\
\hline No & 53 & $(75.7)$ & 70 & $(100.0)$ & 123 & $(87.9)$ & $<0.001$ \\
\hline \multicolumn{8}{|c|}{ Etanercept } \\
\hline Yes & 43 & $(61.4)$ & 0 & $(0.0)$ & 43 & $(30.7)$ & \\
\hline No & 27 & (38.6) & 70 & $\overline{~(100.0)}$ & 97 & (69.3) & $<0.001$ \\
\hline \multicolumn{8}{|c|}{ Adalimumab } \\
\hline Yes & 5 & $(7.1)$ & 0 & $(0.0)$ & 5 & (3.6) & \\
\hline No & 65 & (92.9) & 70 & $(100.0)$ & 135 & (96.4) & $0.058 *$ \\
\hline \multicolumn{8}{|c|}{ Rituximab } \\
\hline Yes & 5 & (7.1) & 0 & $(0.0)$ & 5 & (3.6) & \\
\hline No & 65 & $(92.9)$ & 70 & $(100.0)$ & 135 & $(96.4)$ & $0.058^{*}$ \\
\hline Total & 70 & $(100.0)$ & 70 & $(100.0)$ & 140 & $(100.0)$ & \\
\hline
\end{tabular}

*By Fisher's exact test. The others by the Chi-square test

It is evident in Table (3) that the means of less than those of the control group. all the indicators of BMD were significantly

Table (3): Means of the bone mineral density indicators of the cases and controls

\begin{tabular}{|c||c|c||c||c||c||}
\hline \multicolumn{1}{|||}{} & \multicolumn{2}{c|}{ Case } & \multicolumn{2}{c||}{ Control } & \\
\hline \hline Indicators & Mean & $( \pm$ SD $)$ & Mean & $( \pm$ SD $)$ & P-value* \\
\hline \hline T-spine & -1.54 & $( \pm 1.51)$ & -0.96 & $( \pm 1.09)$ & 0.010 \\
\hline \hline T-femur & -1.24 & $( \pm 1.22)$ & -0.67 & $( \pm 0.87)$ & 0.002 \\
\hline \hline Z-spine & -0.92 & $( \pm 1.48)$ & -0.47 & $( \pm 1.13)$ & 0.048 \\
\hline \hline Z-femur & -0.88 & $( \pm 1.22)$ & -0.41 & $( \pm 0.94)$ & 0.012 \\
\hline
\end{tabular}

*By t-test of two independent sample

Table (4) shows that the prevalence of osteoporosis (according to the T-spine scores) among cases was 22.9\%, compared with $4.3 \%$ of the control group ( $p=0.003)$.
The prevalence of osteoporosis (according to T-femur scores) was $17.1 \%$ among cases and $2.9 \%$ among the controls $(\mathrm{p}=0.003)$. 
Table (4): Bone mineral density as assessed by T-spine and T-femur scores among cases and controls

\begin{tabular}{||c||c||c||c|c||c|c||c||}
\hline \multicolumn{1}{||c||}{} & \multicolumn{2}{c||}{ Case } & \multicolumn{2}{c||}{ Control } & \multicolumn{2}{c|}{ Total } & \\
\hline \hline Scores & No. & $(\%)$ & No. & $(\%)$ & No. & $(\%)$ & P-value \\
\hline \hline T-spine & & & & & & & \\
\hline \hline Osteoporosis & 16 & $(22.9)$ & 3 & $(4.3)$ & 19 & $(13.6)$ & \\
\hline \hline Osteopenia & 30 & $(42.9)$ & 30 & $(42.9)$ & 60 & $(42.9)$ & \\
\hline \hline Normal & 24 & $(34.3)$ & 37 & $(52.9)$ & 61 & $(43.6)$ & 0.003 \\
\hline \hline T-femur & & & & & & & \\
\hline \hline Osteoporosis & 12 & $(17.1)$ & 2 & $(2.9)$ & 14 & $(10.0)$ & \\
\hline \hline Osteopenia & 24 & $(34.3)$ & 17 & $(24.3)$ & 41 & $(29.3)$ & \\
\hline \hline Normal & 34 & $(48.6)$ & 51 & $(72.9)$ & 85 & $(60.7)$ & 0.003 \\
\hline \hline Total & 70 & $(100.0)$ & 70 & $(100.0)$ & 140 & $(100.0)$ & \\
\hline
\end{tabular}

Table (5) considered the cases only. It is evident that the highest prevalence of osteoporosis and osteopenia was among patients aged 50 years or older $(\mathrm{p}=0.001)$. No significant association was detected between bone mineral density (as assessed

Table (5): Bone mineral density of cases as assessed by T-femur scores by the studied factors

\begin{tabular}{|c|c|c|c|c|c|c|c|}
\hline & \multicolumn{6}{|c|}{ T-femur scores categories } & \multirow[b]{3}{*}{ P-value } \\
\hline & \multicolumn{2}{|c|}{ Osteoporosis } & \multicolumn{2}{|c|}{ Osteopenia } & \multicolumn{2}{|c|}{ Normal } & \\
\hline & No. & $(\%)$ & No. & $(\%)$ & No. & $(\%)$ & \\
\hline \multicolumn{8}{|l|}{ Age(years) } \\
\hline $20-29$ & 0 & $(0.0)$ & 0 & $(0.0)$ & 4 & $(100.0)$ & \\
\hline $30-39$ & 3 & $(21.4)$ & 5 & $(35.7)$ & 6 & $(42.9)$ & \\
\hline $40-49$ & 1 & $(4.0)$ & 10 & $(40.0)$ & 14 & $(56.0)$ & \\
\hline (50-59 & 0 & (0.0) & 6 & (42.9) & 8 & (57.1) & \\
\hline $60-69$ & 8 & $(61.5)$ & 3 & $(23.1)$ & 2 & $(15.4)$ & $0.001 *$ \\
\hline \multicolumn{8}{|l|}{ Gender } \\
\hline Female & 11 & $(19.0)$ & 17 & $(29.3)$ & 30 & $(51.7)$ & \\
\hline Male & 1 & $\begin{array}{l}(8.3) \\
\end{array}$ & 7 & $(58.3)$ & 44 & $(33.3)$ & $0.210^{*}$ \\
\hline \multicolumn{8}{|c|}{ Duration of the disease (years) } \\
\hline$<5$ & 1 & $(9.1)$ & 2 & $(18.2)$ & 8 & $(72.7)$ & \\
\hline 5-9 & 2 & $(10.5)$ & 8 & $(42.1)$ & 9 & (47.4) & \\
\hline (10-14 & 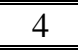 & (18.2) & 9 & (40.9) & 9 & (40.9) & \\
\hline$\geq \geq 15$ & 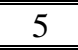 & (27.8) & 5 & $(27.8)$ & 8 & (44.4) & $0.560^{*}$ \\
\hline \multicolumn{8}{|c|}{ BMI $\left(\mathrm{Kg} / \mathrm{m}^{2}\right)$} \\
\hline$<25$ & 5 & $(41.7)$ & 4 & $(33.3)$ & 3 & $(25.0)$ & \\
\hline $25-29$ & 2 & $(10.0)$ & 10 & $(50.0)$ & 8 & $(40.0)$ & \\
\hline$\geq 30$ & 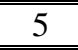 & (13.2) & 10 & $(26.3)$ & 23 & $(60.5)$ & $0.054 *$ \\
\hline \multicolumn{8}{|l|}{ Exercise } \\
\hline Yes & 0 & $(0.0)$ & 7 & $(50.0)$ & 7 & $(50.0)$ & \\
\hline No & 12 & $(21.4)$ & 17 & $(30.4)$ & 27 & $(48.2)$ & $0.095^{*}$ \\
\hline Supplement & & & & & & & \\
\hline
\end{tabular}
$0.210)$, duration of the disease $(\mathrm{p}=0.560)$, BMI $(\mathrm{p}=0.054)$, exercise $(\mathrm{p}=0.095)$, supplement $(\mathrm{p}=0.558)$, systemic disease $(\mathrm{p}$ $=0.862)$, and diabetes $(\mathrm{p}=0.139)$. 
Evaluation of Bone Densitometry in Rheumatoid Arthritis Case Control Study

\begin{tabular}{|c|c|c|c|c|c|c|c|}
\hline Yes & 7 & $(21.2)$ & 12 & $(36.4)$ & 14 & $(42.4)$ & \\
\hline No & 5 & $(13.5)$ & 12 & $(32.4)$ & 20 & $(54.1)$ & 0.558 \\
\hline \multicolumn{8}{|c|}{ Systemic diseases } \\
\hline Yes & 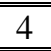 & $(21.1)$ & 6 & $\begin{array}{c}(31.6) \\
\end{array}$ & 9 & $(47.4)$ & \\
\hline No & 8 & (15.7) & 18 & $\begin{array}{l}(35.3) \\
\end{array}$ & 25 & $\begin{array}{l}(49.0) \\
\end{array}$ & 0.862 \\
\hline \multicolumn{8}{|c|}{ Diabetes } \\
\hline Yes & 1 & (16.7) & 0 & $\begin{array}{l}(0.0) \\
\end{array}$ & 5 & (83.3) & \\
\hline $\mathrm{No}$ & 11 & (17.2) & 24 & $\begin{array}{l}(37.5) \\
\end{array}$ & 29 & (45.3) & $0.139 *$ \\
\hline Total & 12 & (17.1) & 24 & $\begin{array}{l}(34.3) \\
\end{array}$ & 34 & (48.6) & \\
\hline
\end{tabular}

*By Fisher's exact test. Others by the Chi-square test

In Table (6) the cases only are included but the BMD was assessed by the T-spine scores. Osteoporosis and osteopenia are mainly prevalent among the cases aged 50 years and above ( $\mathrm{p}<0.001)$. No significant association was detected between BMD with gender ( $\mathrm{p}=$ 0.557), duration of the disease (0.917), BMI

$(\mathrm{p}=0.205)$, exercise $(\mathrm{p}=0.296)$, tea $(\mathrm{p}=$ $0.306)$, supplement $(\mathrm{p}=0.803)$, and systemic disease $(\mathrm{p}=0.429)$. The majority $(83.3 \%)$ of the diabetic had neither osteoporosis nor osteopenia, compared with $29.7 \%$ of those who don't have diabetes $(\mathrm{p}=0.016)$.

Table (6): Bone mineral density of cases as assessed by $\mathrm{T}$-spine scores by the studied factors

\begin{tabular}{|c|c|c|c|c|c|c|c|}
\hline & \multicolumn{6}{|c|}{ T-spine scores categories } & \multirow[b]{3}{*}{ P-value } \\
\hline & \multicolumn{2}{|c|}{ Osteoporosis } & \multicolumn{2}{|c|}{ Osteopenia } & \multicolumn{2}{|c|}{ Normal } & \\
\hline & No. & (\%) & No. & (\%) & No. & (\%) & \\
\hline \multicolumn{8}{|c|}{ Age (year) } \\
\hline $20-29$ & $\bar{~} 0$ & $\begin{array}{l}(0.0) \\
\end{array}$ & 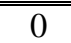 & (0.0) & 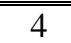 & 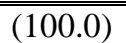 & \\
\hline 30-39 & 1 & $(7.1)$ & $\overline{88}$ & $(57.1)$ & $\overline{5}$ & (35.7) & \\
\hline$\overline{40-49}$ & 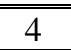 & (16.0) & 11 & (44.0) & 10 & $(40.0)$ & \\
\hline$\overline{50-59}$ & $\overline{1}$ & $(7.1)$ & 9 & $(64.3)$ & 4 & $(28.6)$ & \\
\hline 60-69 & 10 & (76.9) & 2 & $(15.4)$ & 1 & $(7.7)$ & $\frac{\bar{c}<0.001 *}{*}$ \\
\hline \multicolumn{8}{|l|}{ Gender } \\
\hline Female & 14 & (24.1) & 23 & (39.7) & 21 & (36.2) & \\
\hline Male & 2 & (16.7) & 7 & $(58.3)$ & 3 & $(25.0)$ & $0.557 *$ \\
\hline \multicolumn{8}{|c|}{ Duration of the disease } \\
\hline$<<5$ & 1 & $\begin{array}{l}(9.1) \\
\end{array}$ & 6 & $(54.5)$ & 4 & (36.4) & \\
\hline $25-9$ & $\overline{5}$ & (26.3) & 8 & $(42.1)$ & 6 & (31.6) & \\
\hline 10-14 & $\overline{5}$ & (22.7) & 10 & $(45.5)$ & 7 & $(31.8)$ & \\
\hline$\geq 15$ & $\overline{5}$ & (27.8) & 6 & (33.3) & 7 & (38.9) & $0.917 *$ \\
\hline \multicolumn{8}{|c|}{ BMI $\left(\mathrm{Kg} / \mathrm{m}^{2}\right)$} \\
\hline$<25$ & 5 & (41.7) & 3 & $(25.0)$ & 4 & (33.3) & \\
\hline $25-29$ & 6 & (30.0) & 7 & (35.0) & 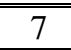 & $(35.0)$ & \\
\hline$\geq 30$ & $\overline{5}$ & (13.2) & 20 & (52.6) & 13 & $(34.2)$ & $0.205^{*}$ \\
\hline \multicolumn{8}{|c|}{ Exercise } \\
\hline Yes & 1 & (7.1) & 7 & $(50.0)$ & $\overline{6}$ & $(42.9)$ & \\
\hline No & 15 & (26.8) & 23 & (41.1) & 18 & (32.1) & $0.296^{*}$ \\
\hline \multicolumn{8}{|c|}{ Supplement } \\
\hline Yes & 8 & (24.2) & 15 & (45.5) & 10 & (30.3) & \\
\hline No & 8 & (21.6) & 15 & (40.5) & 14 & (37.8) & 0.803 \\
\hline \multicolumn{8}{|c|}{ Systemic diseases } \\
\hline Yes & 6 & (31.6) & 6 & (31.6) & 7 & $(36.8)$ & \\
\hline
\end{tabular}


Evaluation of Bone Densitometry in Rheumatoid Arthritis Case Control Study

\begin{tabular}{||c||c||c||c||c||c||c|c|}
\hline No & 10 & $(19.6)$ & 24 & $(47.1)$ & 17 & $(33.3)$ & 0.429 \\
\hline Diabetes & & & & & & & \\
\hline \hline Yes & 1 & $(16.7)$ & 0 & $(0.0)$ & 5 & $(83.3)$ & \\
\hline \hline No & 15 & $(23.4)$ & 30 & $(46.9)$ & 19 & $(29.7)$ & $0.016^{*}$ \\
\hline \hline Total & 16 & $(22.9)$ & 30 & $(42.9)$ & 24 & $(34.3)$ & \\
\hline
\end{tabular}

*By Chi-square test and Fisher's exact test

\section{Discussion}

Osteoporosis and fractures are two common complications in patients with RA and that affect quality of life [23]. This study was done to evaluate bone mineral density in patients with rheumatoid arthritis and compare it with bone mineral density in healthy control.

Our results support the prevalence of osteoporosis (according to the T-spine scores) among cases was $22.9 \%$, compared with $4.3 \%$ of the control group, and the prevalence of osteoporosis (according to $\mathrm{T}$ femur scores) was $17.1 \%$ among cases and $2.9 \%$ among the controls. These results are similar to those of Brand et al [24] they found that low BMD higher in RA patients than normal age and gender-matched populations. The status of bone mass in RA has been investigated in some case-control and longitudinal studies [25-29]. Bone mass in RA was shown to be lower compared with non-RA controls. This study also found that $34.3 \%$ of rheumatoid arthritis patients had normal BMD at the spine, $42.9 \%$ had osteopenia, compared with the control group $52.9 \%$ had normal BMD, 43.6\% had osteopenia which was in agreement with the cohort study, $43.3 \%$ had normal BMD, and $43.3 \%$ had osteopenia, at the lumbar spine [30], regarding femur $48.6 \%$ of RA patients had normal BMD and $34.3 \%$ had osteopenia compare with control group were $72.9 \%$, $24.3 \%$. Zhang et al [31] found that rheumatoid arthritis had either osteoporosis or osteopenia in the lumbar spine, and $44.9 \%$ had either osteoporosis and osteopenia in the femoral neck.

In the current study lumbar spine was the most common site for RA patients $22.9 \%$, followed by the femur neck $17.1 \%$, these findings are in agreement with the study done by Eman et al [30] they reported that lumbar spine was the most common site for osteoporosis in RA patients followed by the femur.

In this study, female more commonly affected by in rheumatoid arthritis females (24.1\%) than in men with RA (16.7\%) which is in agreement with the research done by Yoon et al [32] found that patient with rheumatoid arthritis were arranged by gender the prevalence of osteoporosis in the female are more common than in the male.

In the present study, it is evident that the patients with age 50 years or older had more chance for developing osteoporosis and osteoporosis at the femur $(\mathrm{P}=0.001)$, also patients with age 50 years or above were more prevalent for osteoporosis and osteopenia at the spine $(\mathrm{P}<0.001)$, which were significant. It is known that low bone mineral density (BMI) and age are associated factors of osteoporosis in patients with RA as well as non-rheumatoid arthritis population, osteoporosis and osteopenia in both spine and femur more common in the thinner patients but this was not significant which was in agreement with the study done by Mobini et 
al. [33] this study reported that age and BMI were associated factors of decreased BMD and osteoporosis in RA.

Our rheumatoid arthritis patients with osteoporosis who had long RA duration than those had no osteoporosis, but this difference not significant $(\mathrm{P}=0.56)$, this result in agreement with those done by Eman et al [30]. And Sinigaglia et al [34] they also found that rheumatoid arthritis patients with spine or femoral osteoporosis had longer disease duration, these results are consistent with those Güler-Yüksel et al [35] they reported that decreased BMD and aggressive joint disease found in RA patients with early ,active, erosive diseases and a positive rheumatoid. The other factors including disease duration, exercise, taking the supplement and systemic disease in the development of osteoporosis was not significant.

\section{Conclusions}

In conclusion the reduction of BMD was more common in patients with rheumatoid arthritis than in the control group. Decrease BMD is not necessarily correlated with disease duration, BMI, systemic diseases supplement or regular exercise. DEXA scanning is the most accurate diagnostic method for evaluating osteoporosis in patients with RA. Our study has some limitations.

\section{Recommendations}

BMD was detected once in each patient, so we recommend doing another study and measuring BMD more than one time and comparing itwith different therapy taken by the patient.

\section{Source of funding: Nill}

Ethical clearance: This study was approved by the Ethical Committee at the college of Medicine in the Hawler Medical University.

Conflict of interest: This research done by one researcher.

\section{References}

[1]Chung SJ, Kwon YJ, Park MC, Park YB, Lee SK. The correlation between increased serum concentrations of interleukin-6 family cytokines and disease activity in rheumatoid arthritis patients. Yonsei Med J. 2011;52: 113-20.

[2]Vis M, Guler- Yuksel M, Lems WF. Can bone loss in rheumatoid arthritis be prevented? Osteoporos Int. 2013;24(10):2541-53.

[3]Turesson C, O'Fallon WM, Crowson CS, Gabriel SE, Matteson EL.Extra-articular disease manifestations in rheumatoid arthritis: incidence trends and risk factors over 46 years. Ann Rheum Dis. 2003;62(8):722-7.

[4]Symmons DP. Epidemiology of rheumatoid arthritis: determi- nants of onset, persistence and outcome. Best Pract Res Clin Rheumatol. 2002;16(5):707-22.

[5]Alamanos Y, Drosos AA. Epidemiology of adult rheumatoid arthritis. Autoimmun Rev. 2005;4(3):130-6.

[6]Raterman HG, Hoving JL, Nurmohamed MT, Herenius MM, Sluiter JK, Lems WF, et al. Work ability: a new outcome measure in rheumatoid arthritis? Scand J Rheumatol. 2010;39(2):127-31.

[7]Oulson KA, Reed G, Gilliam BE, Kremer JM, Pepmueller PH. Factors influencing fracture risk, $\mathrm{T}$ score, and management of 
osteoporosis in patients with rheumatoid arthritis in the Consortium of Rheumatology Researchers of North America (CORRONA) registry. J Clin Rheumatol 2009; 15: 155-60. [8]Mundy GR. Osteoporosis and inflammation. Nutr Rev 2007; 65: S147-51.

[9]Oelzner P, Hein G. Inflammation and bone metabolism in rheumatoid arthritis. Pathogenetic viewpoints and therapeutic possibilities. Med Klin (Munich) 1997; 92: 607-14.

[10]Cortet B, Flipo RM, Blanckaert F, Evaluation of bone mineral density in patients with rheumatoid arthritis. Influence of disease activity and glucocorticoid therapy. Rev Rhum Engl Ed 1997; 64: 451-8. [11]Lean RF, Buijs WC, Verbeek AL, et al. Bone mineral density in patients with recent onset rheumatoid arthritis: influence of disease activity and functional capacity. Ann Rheum Dis 1993; 52: 21-6.

[12]Cortet B, Guypt MH, Solau E, et al. Factors influencing bone loss in rheumatoid arthritis: a longitudinal study. Clin Exp Rheumatol 2000; 18: 683-90.

[13]Wijbrandts CA, Klaasen R, Dijkgraaf MGW, Gerlag DM, vanEck-Smit BLF, Tak PP. Bone mineral density in rheumatoid arthritis patients 1 year after adalimumab therapy: Arrest of bone loss. Ann Rheum Dis. 2009; 68:373-6.

[14]Aizer J, Reed G, Onofrei A, Harisson MJ. Predictors of bone density testing in patients with rheumatoid arthritis. Rheumatol Int. 2009; 29:897-905.

[15]Dimitroulas T, Nikas SN, Trontzas P, Kitas GD. Biologic therapies and systemic bone loss in rheumatoid arthritis. Autoimmun Rev. 2013;12(10):958-66.
[16]Emery P, Dorner T. Optimizing treatment in rheumatoid arthritis: a review of potential biological markers of response. Ann Rheum Dis. 2011;70(12):2063-70.

[17]Venkateshan SP, Sidhu S, Malhotra S, Pandhi P. Efficacy of biologicals in the treatment of rheumatoid arthritis. a metaanalysis. Pharmacology. 2009;83(1):1-9.

[18]Keystone E. Recent concepts in the inhibition of radiographic progression with biologics. Curr Opin Rheumatol. 2009;21(3):231-7.

[19]Leib ES ,Lewiecki EM ,Binkley N ,Hamdy RC. Official positions of the International Society for Clinical Densitometry. J Clin Densitom. 2004; 7:1-6. [20]Centers for Disease Control and Prevention. Credible health information, 2009, http://www.cdc.gov/healthyweight/ assessing/bmi/adult BMI/index.html.

[21]Assessment of fracture risk and its application to screening for postmenopausal osteoporosis. Report of a WHO Study Group. World Health Organ Tech Rep Ser 1994, 843:1-129.

[22]Baim S, Leonard MB, Bianchi ML, Hans DB, Kalkwarf HJ, Langman CB, Rauch F: Official Positions of the International Society for Clinical Densitometry and executive summary of the 2007 ISCD Pediatric Position Development Conference. J Clin Densitom 2008, 11:6-21.

[23] Ranganathan P. Genetics of bone loss in rheumatoid arthritis role of vitamin D receptor polymorphisms. Rheumatology (Oxford). 2009; 48:342-6.

[24]Brand C, Lowe A, Hall S. The utility of clinical decision tools for diagnosing osteoporosis in postmenopausal women with 
rheumatoid arthritis. BMC Musculoskelet Disord. 2008; 9:13.

[25]Heidari B, Jalali F. Bone densitometry in patients with Rheumatoid arthritis. Acta Med Iran 2005; 43: 99-104. [26] $26 . \quad$ di Munno O, Mazzantini M, Sinigaglia L, et al. Effect of low dose methotrexate on bone density in women with rheumatoid arthritis: results from a multicenter cross- sectional study. J Rheumatol 2004; 31: 1305-9.

[27]Haugeberg G, Ørstavik RE, Kvien TK. Effects of rheumatoid arthritis on bone. Curr Opin Rheumatol 2003; 15: 469-75. [28] Haugeberg G, Ørstavik RE, Uhlig T, et al. Bone loss in patients with rheumatoid arthritis: results from a population-based cohort of 366 patients followed up for two years. Arthritis Rheum 2002; 46: 1720- 8 [29]Shankar S, Handa R, Aneja R, et al. Bone mineral density in Indian women with rheumatoid arthritis. Rheumatol Int 2009; 29: 377-81.

[30]Eman A. Hafez, Howaida E. Mansour, Sherin H. Hamza, Sherine George Moftah, Takwa Badr Younes and Mona Ahmed Ismail. Bone Mineral Density Changes in Patients with Recent-Onset Rheumatoid Arthritis.Clinical Medicine Insights: Arthritis and Musculoskeletal Disorders 2011:4 8794.

[31]Zhang J, Redden DT, McGwin G Jr, et al. Generalized bone loss as a predictor of three-year radiographic damage in African American patients with recent-onset rheumatoid arthritis. Arthritis Rheum. 2010; 62:2219-26.

[32]Yoon J, Kwon SR,Lim MJ, et al. A comparison of three different guidelines for osteoporosis treatment in patients with rheumatoid arthritis in Korea. Korean J Intern Med. 2010; 25:436-46. [33]Mobini M, Kashi Z, Ghobadi far A. Prevalence and associated factors of osteoporosis in female patients with rheumatoid arthritis. Caspian J Intern Med 2012; 3: 421- 4.

[34]Sinigaglia L, Nervetti A, Mela Q, et al. A multicenter cross sectional study on bone mineral density in rheumatoid arthritis. Italian Study Group on Bone Mass in Rheumatoid Arthritis. J Rheumatol. 2000; 27:2582-9.

[35]Güler-Yüksel M, Bijsterbosch J, Goekoop -Ruiterman YP, et al. Bone mineral density in patients with recently diagnosed, active rheumatoid arthritis. Ann Rheum Dis. 2007; 66:1508-12. 